\title{
Synchronized Phasor Measurements with GPS Time Stamping using 64 Point DFT in PMU
}

\author{
R.Alekya, Ravi Ponnala, Aleti Soumya, B. Shiny Sucharitha
}

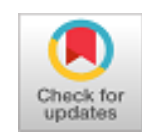

\begin{abstract}
This paper describes about the time synchronization of different locations voltage or current signals for accurate comparison of signals on single phasor graph, all the measured phasors are synchronized with Global Positioning System (GPS) time stamping. Day to day power demand increases very rapidly, to meet the growing demand of electrical energy new energy resources are required and manage them efficiently. For efficient allocation of sources there should be a good monitoring and fast control system. For better monitoring and control of the system accurately it requires "Wide Area Monitoring" of power system. In the wide area monitoring system collection of data from the power system should be at a faster level. The collection of data from the power system at faster level is possible by using "Phasor Measurement Units(PMUs)". PMU collects the data at faster rate rates like 50-60 samples for cycle, this information is send to local Phasor Data Concentrator (PDC). Local phasor data concentrator collects the data from different PMUs which are located in different areas. This PDC helps to take the necessary action on power system. For synchronization, pulse per second(PPS) is taken from GPS module. From this 1PPS, 3200 pulses is generated for high accuracy of 64 point DFT of $50 \mathrm{~Hz}$ signal using microcontroller. System frequency is calculated by using time period between the two consecutive raising edges or falling edges of square wave. This is in synchronous with the input sinusoidal signal.
\end{abstract}

Key words: GPS, phase angle, PMU, 1PPS, magnitude, frequency.

\section{INTRODUCTION}

The world becomes a smarter day to day. The power system basic operation and control block diagram is shown in Fig.1. It is very much required to implement real time monitoring of the system because to meet the growing demand of the power system the strongest things is the renewable energy sources [2]. The renewable energy sources or distributed energy sources are connected at low or medium voltage levels of the power system. Due to the random nature of availability of the renewable energy sources may cause operational and

Revised Manuscript Received on April 27, 2020.

* Correspondence Author

R.Alekya*, EEE Department, St.Martin's Engineering College, Hyderabad, India. Email:alekyaa07@gmail.com

Ravi Ponnala, EEE Department, Vasavi Collegr of Engineering, Hyderabad, India. Email: ravi.ponnala237@gmail.com

Aleti Soumya, EEE Department, St.Martin's Engineering College, Hyderabad, India.. Email: soumyayadama@gmail.com

B.Shiny Sucharitha, EEE Department, St.Martin's Engineering College, Hyderabad, India.. Email: shinylucky5@gmail.com

(C) The Authors. Published by Blue Eyes Intelligence Engineering and Sciences Publication (BEIESP). This is an open access article under the CC BY-NC-ND license (http://creativecommons.org/licenses/by-nc-nd/4.0/) technical difficulties in the power systems. The major disadvantage with the existing system is that the measurements are not synchronized [3]. The PMU estimates a sinusoidal quantity in a power system in the form of magnitude (RMS) and phase angle or real and imaginary values. These values are time stamped with GPS timing for synchronization of different PMU readings which are located at various areas in the world [4]. By using synchronized phasor measurements various aspects like real time demand scheduling, fault detection, phase angle of voltage or current, frequency, rate of change of frequency and state estimation is possible [5]. That means PMUs are introduced new things like measuring of fundamental component of the signal, phase angle etc.

The fundamental component of the signal is extracted from the distorted signal by using the butterworth filter. By Appling the Discrete Fourier Transform (DFT) the magnitude and phase angle of the signal is estimated. This is also helpful for the power spectrum analyzer [6].

The PMU measures the magnitude of the voltage at connected bus and all the incident branch currents of that bus. These values are time stamped with GPS [7] timing and transferred together via the communication module to a server (PDC) [8].

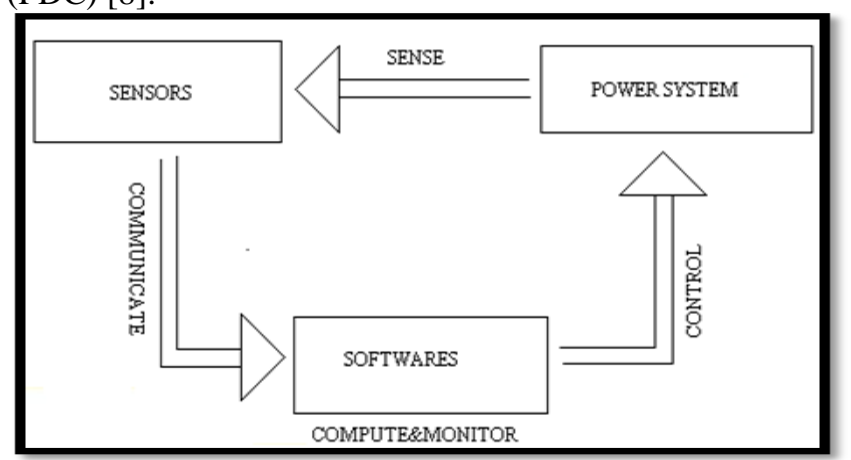

Fig. 1. Basic block diagram representation of power system

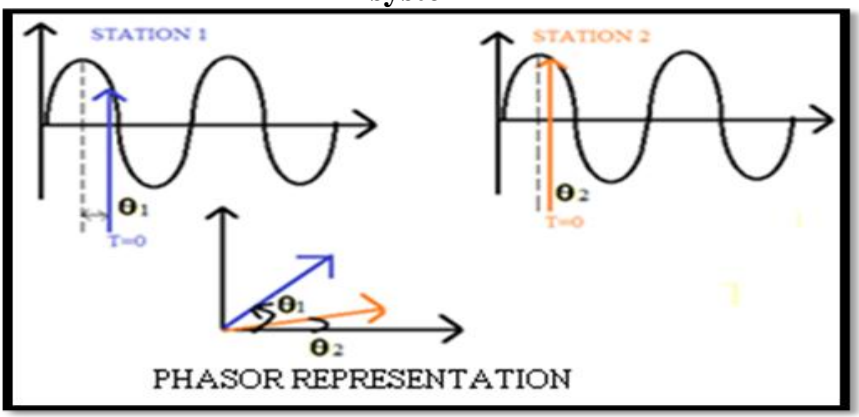

Fig. 2. Phasor measurement comparison

Published By:

Blue Eyes Intelligence Engineering \& Sciences Publication

(C) Copyright: All rights reserved. 


\section{GLOBAL POSITIONING SYSTEM (GPS):}

For PMU measurements synchronization the reference time signal is taken from GPS NEO6MV2 module. This GPS module gives 1PPS it is applied to Arduino to generate required number of pulses is called Global positioning System Disciplined Oscillator (GPSDO). This is shown in Fig.4.

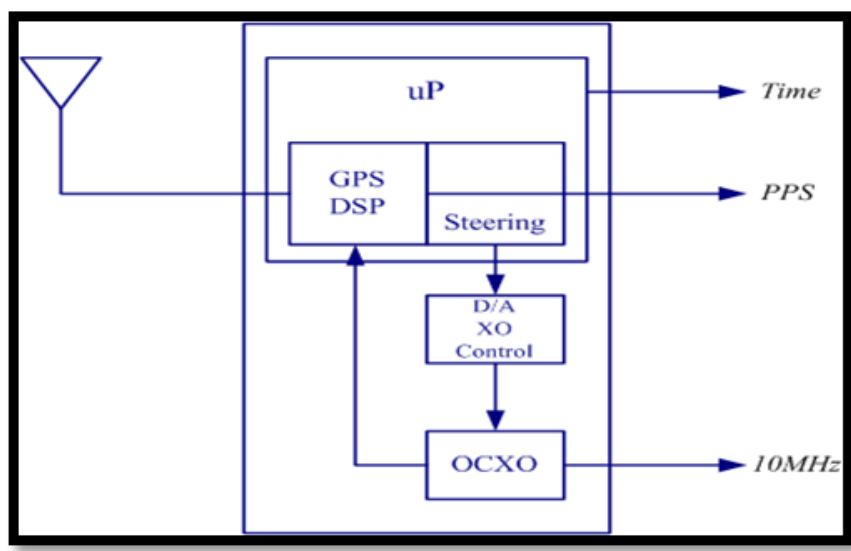

Fig. 3. GPSDO block diagram representation.

NEO6MV2 GPS Module have four terminals. Vcc-Supply Voltage(2.7 to 3.6V), Gnd-Ground pin, TX and RX-These 2 pins acts as an UART interface for communication. TX must be connect Rx pin of the Arduino and RX pin should connect Tx pin of the Arduino. The 1PPS signal is converted into 3200(64*50) pulses per second by Arduino Uno[9]. These 3200 pulses are equally time spaced with $0.3125 \mathrm{msec}$.

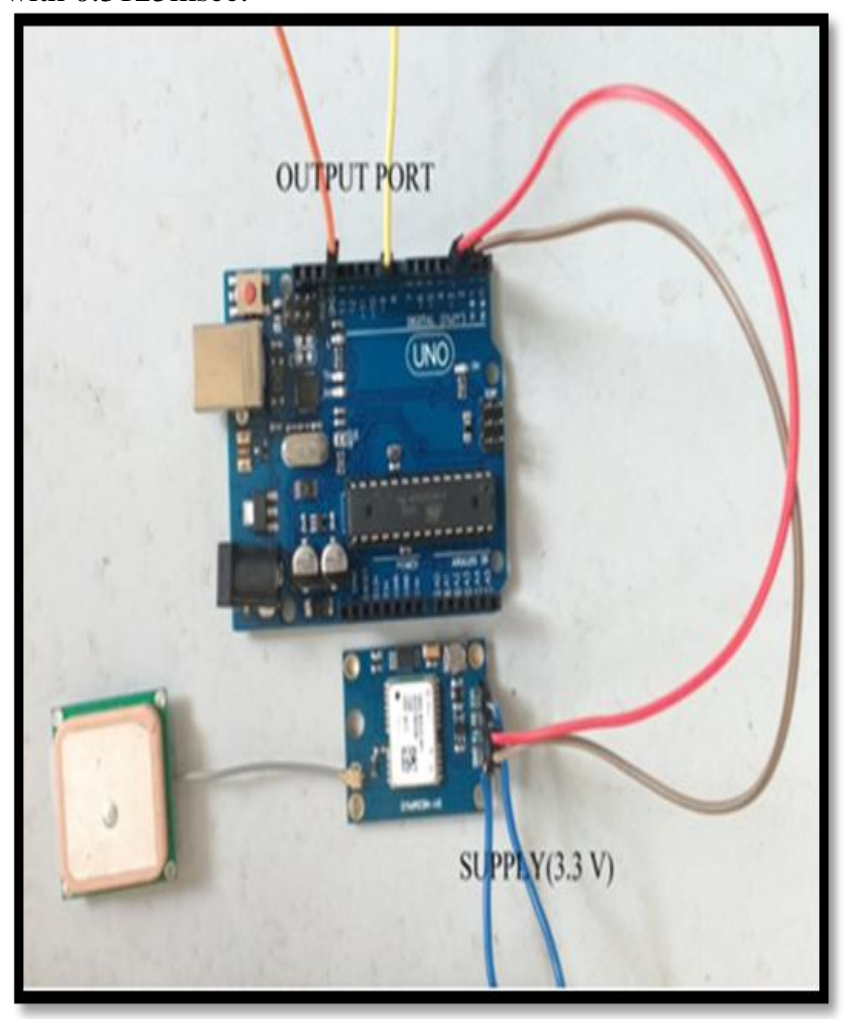

Fig. 4. Physical connection of GPS to Arduino

Once pulse is received from the GPS counter starts and generating required number of pulses [10]. The flow chart of GPSDO is shown in Fig.5.

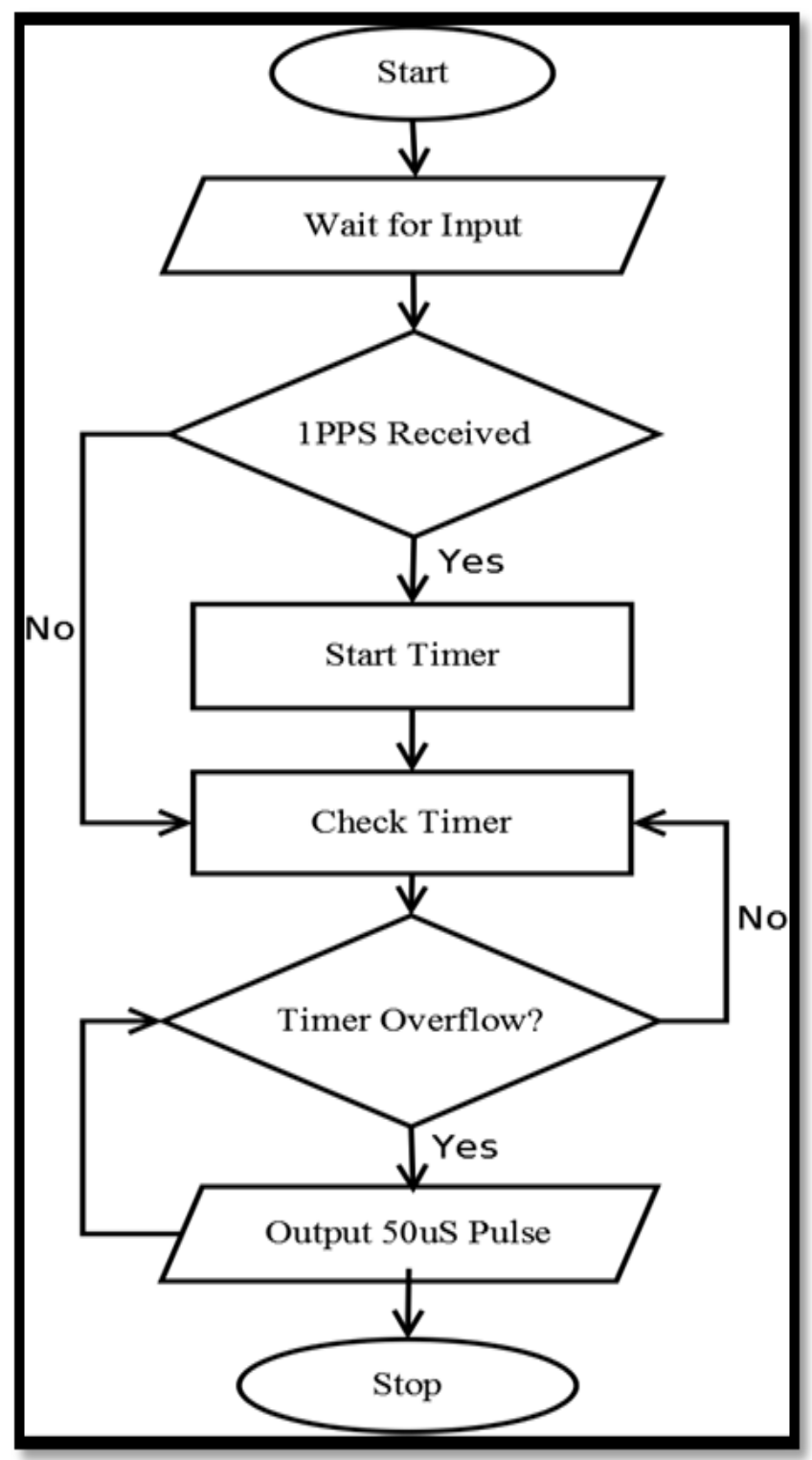

Fig.5 Flow Chart of GPSDO

arduino programming code for GPSDO is shown below. In arduino IDE software install the TimerOne.h heder file and then program can execute.

\#include < TimerOne.h>

const int sampling_clock_out_pin = 9;

void setup()

\{

pinMode(2, INPUT);

attachInterrupt(0, pulsePPS, RISING);

Timer1.initialize(312.5);

Timer1.pwm(sampling_clock_out_pin , 100);

$$
\text { \} }
$$

void $\operatorname{loop}()$

void pulsePPS()

\{

Timer1.restart();

\}

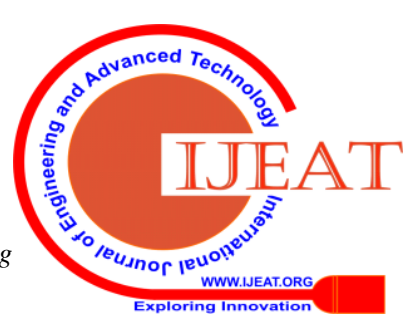




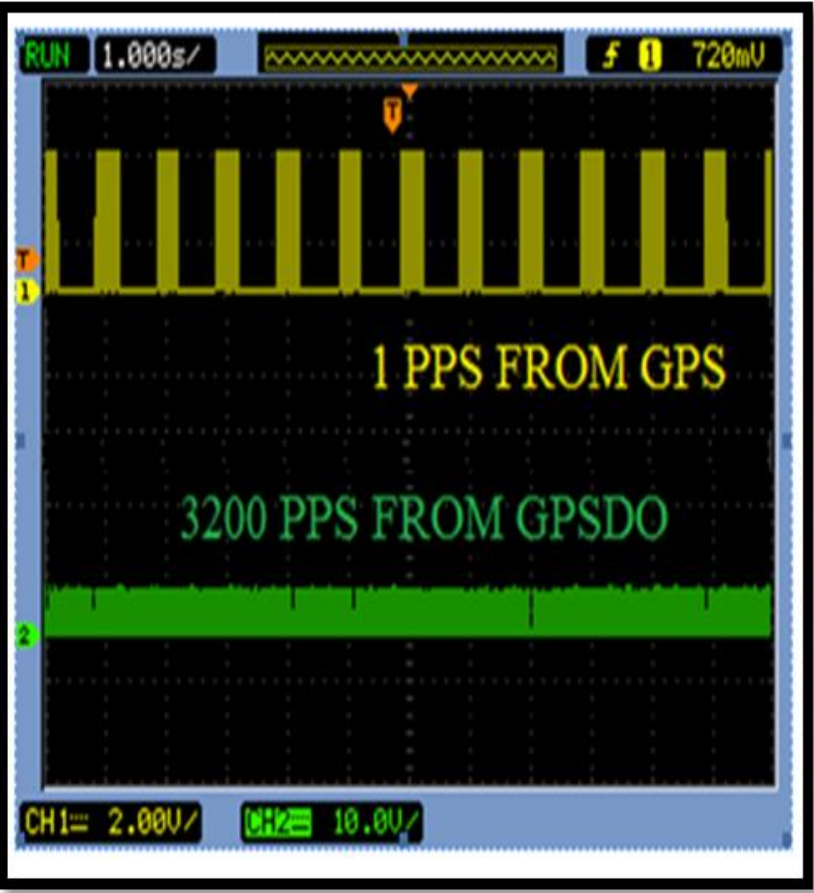

Fig. 6. 1 PPS from GPS and Respective output pulses of GPSDO

In the fig. 6 it is shown that the 1PPS is converted into required number of pulses(3200). For clear observation it is shown in Fig.7.

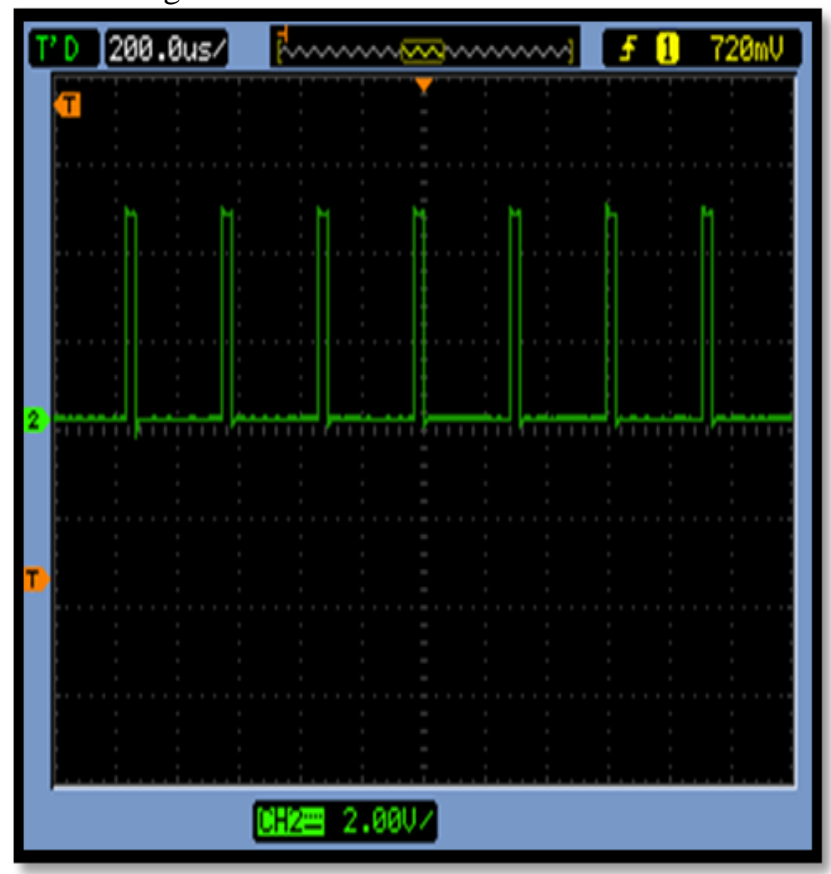

Fig. 7. 3200 Pulses Per Second from GPSDO

In the fig. 7 it is shown that the time period between the any two pulses is $1.6 * 200 \mathrm{US}=3.2 \mathrm{mS}$ or it will generate 3200 pulses per second. The

\section{TEST SYSTEM}

Let us consider a four bus system, in which the two PMUs are located at station 1 and station 2. These two PMUs will calculate the magnitude of that bus voltage and all the incident branch currents [11]. Based on the branch currents and branch impedances the other bus voltages can be estimated.

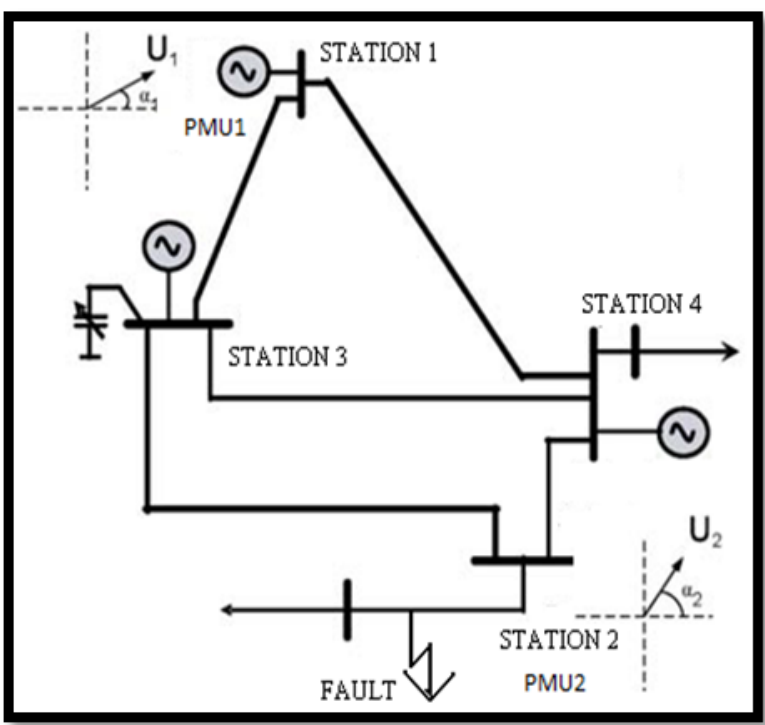

Fig. 8. Four bus model test system.

In order to calculate phasor of system, Window system is used in DFT. Impulse input to a system may give Finite Impulse Response (FIR) or Infinite Impulse Response (IIR) [12]. The analysis of IIR is difficult, so to take finite series response window (Rectangular or Kaiser or Hamming) is useful. In this window input signal is sampled at $\mathrm{f}_{\mathrm{s}}=\mathrm{Nf}$ $\left(\mathrm{f}_{\mathrm{s}}=64 * 50=3200\right)$ and sampling time $\mathrm{T}_{\mathrm{s}}=1 / \mathrm{f}_{\mathrm{s}}\left(\mathrm{T}_{\mathrm{s}}=1 / 3200=\right.$ $0.0003125 \mathrm{sec}$ ) Where $\mathrm{f}_{\mathrm{s}}$ is sampling frequency, $\mathrm{N}$ is window size, $f$ is input signal frequency and $T_{s}$ is sampling time period.

By considering fault occur at the bus station 2 and normal working conditions at bus station 1 the PMU readings are shown in below Fig.9 The branch signal will gets disturbed due to harmonics present in the fault, the corresponding simulated waveform with magnitude and phase angle variations are shown in fig. 10 .

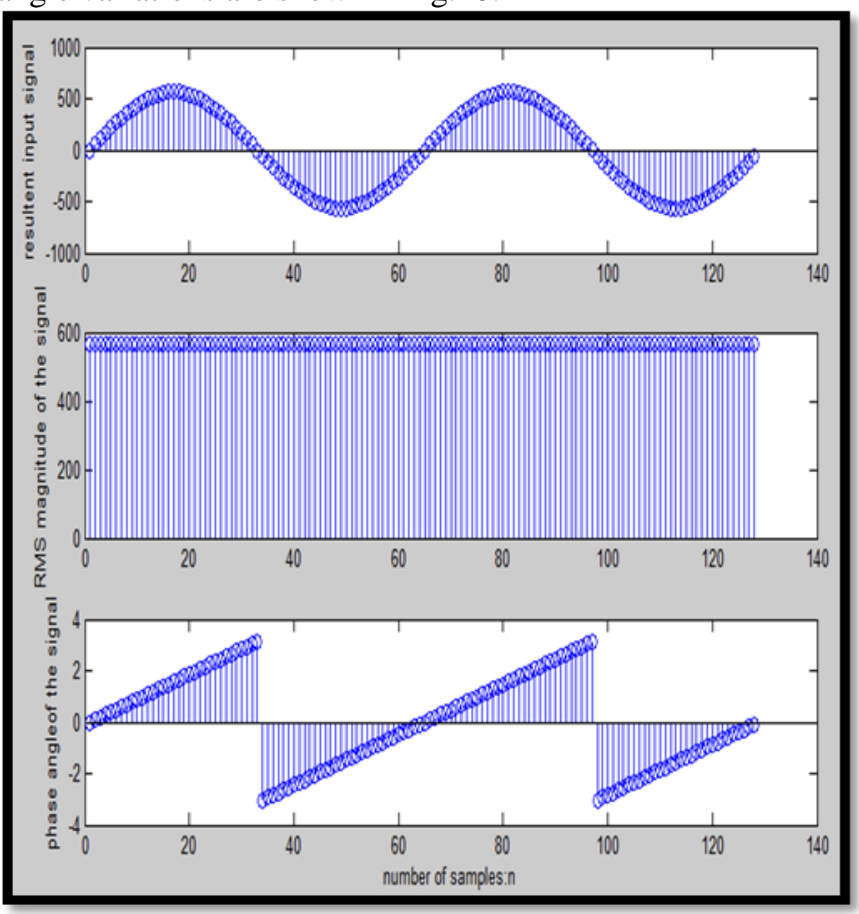

Fig. 9. PMU1 signal, magnitude and phase angle readings

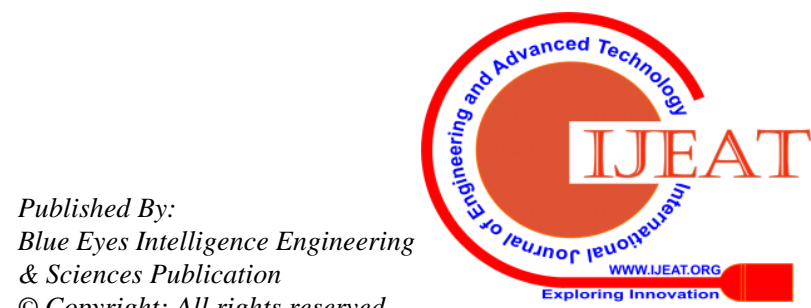


A distorted, periodic waveform is shown in fig.10. It consist of a different odd harmonic components. The distorted waveform, magnitude and phase angles are simulated and it is shown in Fig. 10.

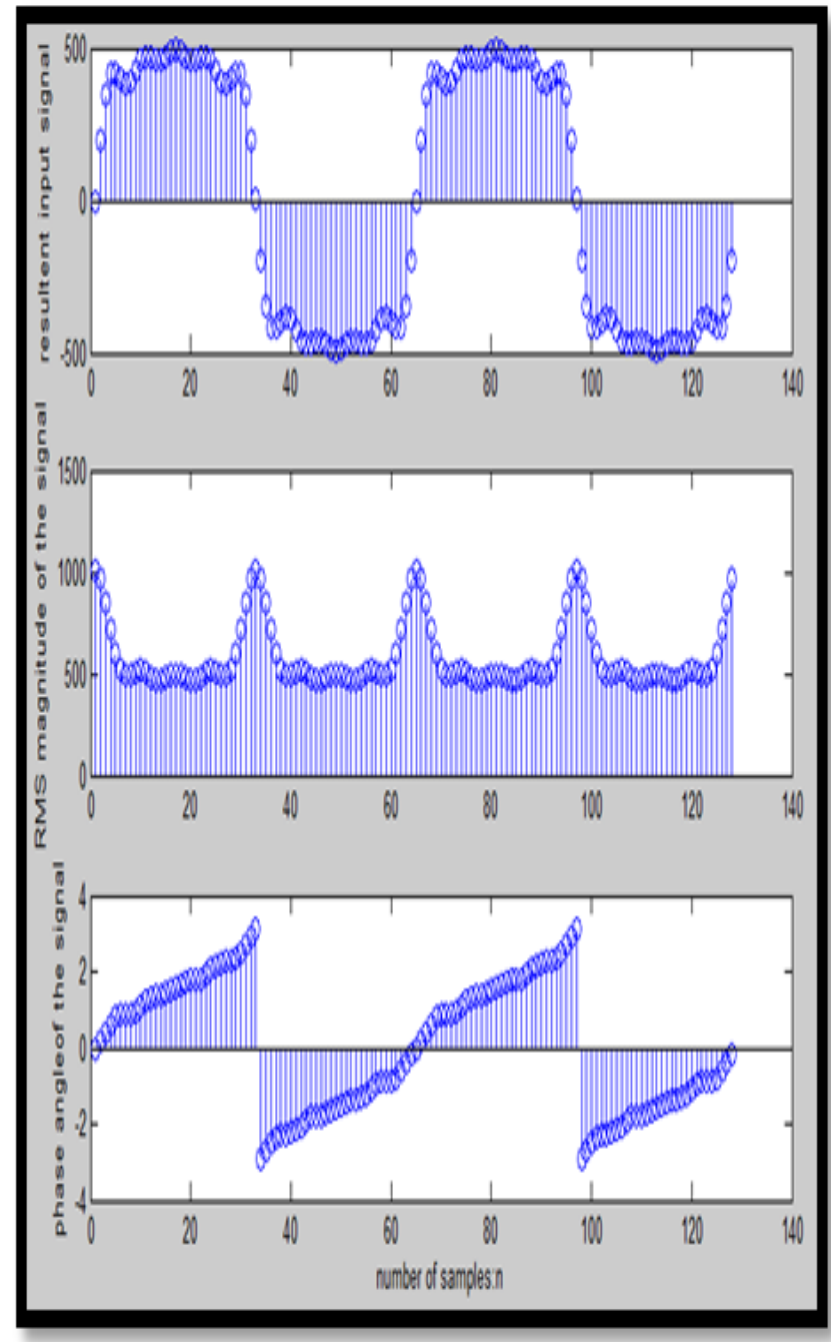

Fig. 10. PMU2 signal, magnitude and phase angle readings

\section{PHASOR CALCULATION AND TIME STAMMPING}

The readings of the two PMUs are time stamped with GPS timing which is shown in table 1. PMUs are calculating the magnitude and phase angles using Discrete Fourier Transform (DFT). In DFT for magnitude and phase angle calculation, Non-Recursive based algorithm is used [1]. In each window 64 samples are taken $(\mathrm{N}=64)$ to calculate magnitude and phase angle.

Normally the sinusoidal waveform is represented with

$X(t)=X_{m} \cos (2 \pi f t+\varphi)$

The phasor form of the signal is given by

$x(t)=X_{\text {rms }} \mathrm{e}^{\mathrm{j} \Phi}=X_{\text {rms }}[\cos \Phi+j \sin \Phi]---(2)$

The measured values are coordinated to universal coordinated time (UTC). System frequency can be calculated by using sine to square wave converter. This converts the sine wave signal into square wave signal for easy calculation of time period of the signal [13]. The frequency of the signal is " $f=1 / T$ ", where $\mathrm{T}$ is the time period between two consecutive raising edges or falling edges. The single phase sine to square wave converter is shown in fig. 11, and respective output square wave is shown in fig. 12 .

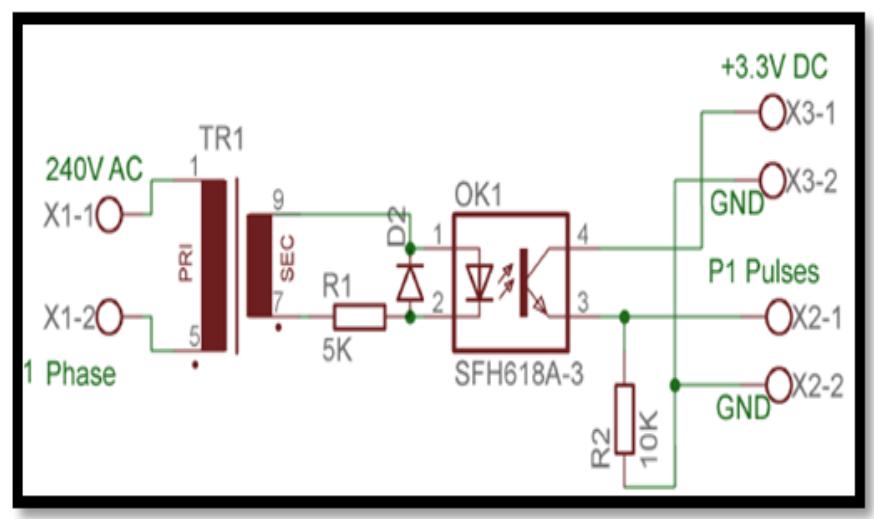

Fig. 11. sine to square wave converter

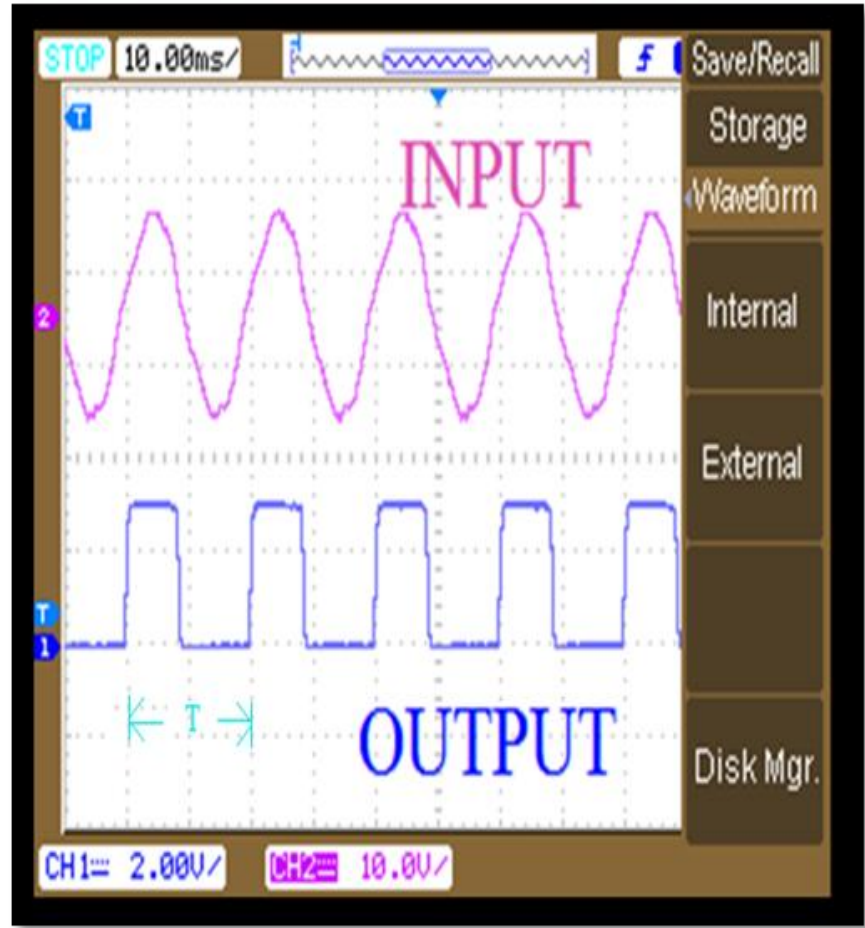

Fig. 12 Square wave signal for frequency estimation

\section{V.NON-RECURSIVE DFT ALGORITHM FOR PHASOR CALCULATION}

The normal DFT equations for measurement of the the magnitude and phase angle is

$$
\begin{aligned}
& X^{N-1}=\frac{\sqrt{2}}{N} \sum_{n=0}^{N-1} x_{n}[(\cos (n \theta)-j \sin (n \theta)] \\
& X^{N}=\frac{\sqrt{2}}{N} \sum_{n=0}^{N-1} x_{n+1}[(\cos (n \theta)-j \sin (n \theta)]
\end{aligned}
$$

In recursive algorithm first data window is computed for $n=0$ to $\mathrm{n}=\mathrm{N}-1$ and in next window $\mathrm{n}=0$ value is omitted and $\mathrm{n}=\mathrm{N}$ sample is included means in further windows next coming sample is including and respective starting samples are excluding. Recursive algorithm is numerically less stable because if error occur in first window that will be carry forward to next windows also.

\section{Published By:}

Blue Eyes Intelligence Engineering \& Sciences Publication

(C) Copvriaht: All riahts reserved.

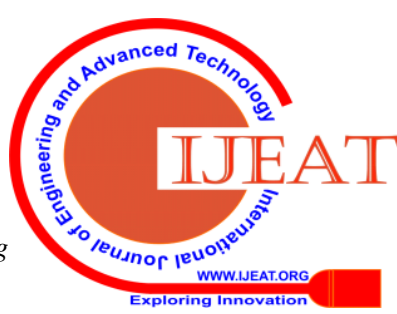


This will greatly effect on the total system window computations so non-recursive algorithm is mostly used in all applications.

The MATLAB sample program for phasor calculation is shown below.

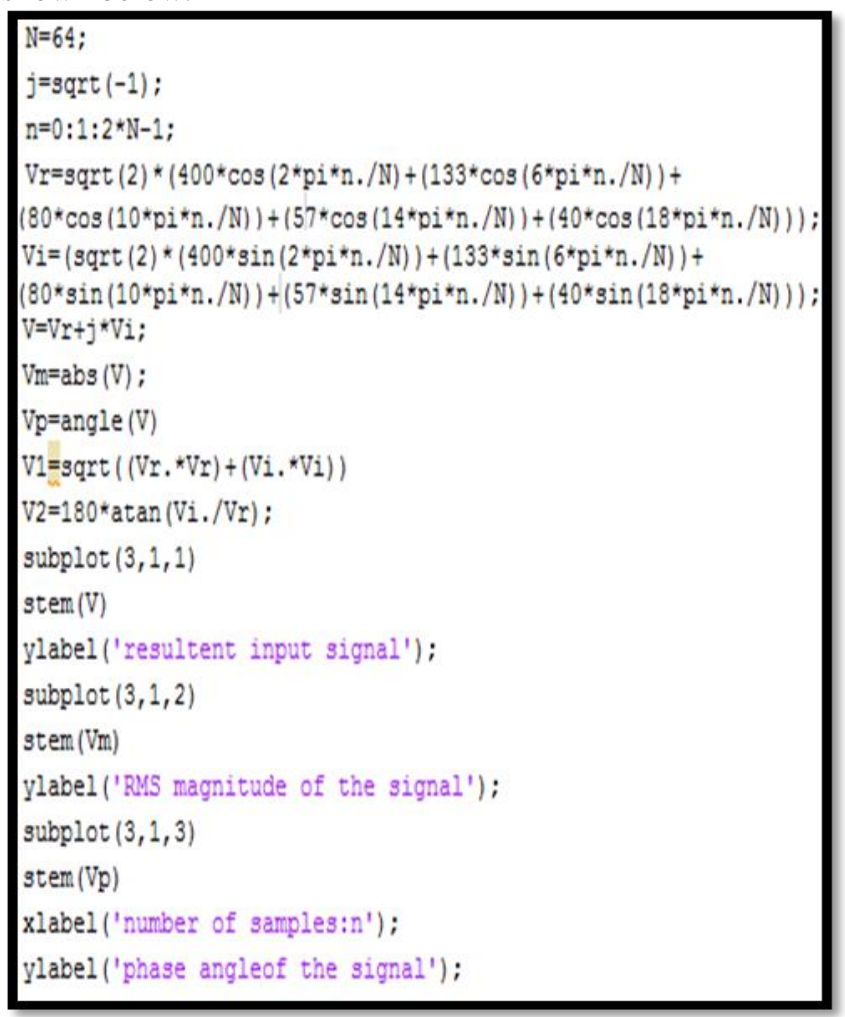

Table 1. Non-recursive DFT based phasor estimation

\begin{tabular}{|c|c|c|c|c|}
\hline $\begin{array}{c}\text { Time } \\
\text { stamping } \\
\text { (in } \\
\text { Seconds) }\end{array}$ & $\begin{array}{c}\text { Magnitud } \\
\boldsymbol{e}\end{array}$ & $\begin{array}{c}\text { Phase angle } \\
\text { (rad) }\end{array}$ & Magnitude & $\begin{array}{c}\text { Phase angle } \\
\text { (rad) }\end{array}$ \\
\hline 0 & 565.68 & 0 & 1004.09 & 0 \\
\hline 0.0003 & 565.68 & 0.0982 & 961.7088 & 0.2083 \\
\hline 0.0006 & 565.68 & 0.1963 & 852.1216 & 0.4180 \\
\hline 0.0009 & 565.68 & 0.2945 & 716.7552 & 0.6188 \\
\hline 0.0013 & 565.68 & 0.3927 & 597.0496 & 0.7797 \\
\hline 0.0016 & 565.68 & 0.4909 & 518.7392 & 0.8654 \\
\hline 0.0019 & 565.68 & 0.5890 & 489.7408 & 0.8871 \\
\hline 0.0022 & 565.68 & 0.6872 & 496.6336 & 0.9107 \\
\hline 0.0025 & 565.68 & 0.7854 & 511.5328 & 0.9822 \\
\hline 0.0028 & 565.68 & 0.8836 & 514.368 & 1.0967 \\
\hline 0.0031 & 565.68 & 0.9817 & 502.0544 & 1.2214 \\
\hline 0.0034 & 565.68 & 1.0799 & 482.2464 & 1.3182 \\
\hline 0.0037 & 565.68 & 1.1781 & 466.5408 & 1.3663 \\
\hline 0.0041 & 565.68 & 1.2763 & 464.6016 & 1.3825 \\
\hline 0.0044 & 565.68 & 1.3744 & 475.9168 & 1.4097 \\
\hline 0.0047 & 565.68 & 1.4726 & 489.79 & 1.4752 \\
\hline 0.0050 & 565.68 & 1.5708 & 495.6864 & 1.5708 \\
\hline 0.0053 & 565.68 & 1.6690 & 489.792 & 1.6664 \\
\hline 0.0056 & 565.68 & 1.7671 & 475.9168 & 1.7319 \\
\hline 0.0059 & 565.68 & 1.8653 & 464.6016 & 1.7591 \\
\hline 0.0063 & 565.68 & 1.9635 & 466.5408 & 1.7753 \\
\hline 0.0066 & 565.68 & 2.0617 & 482.2464 & 1.8234 \\
\hline 0.0069 & 565.68 & 2.1598 & 502.0544 & 1.9202 \\
\hline 0.0072 & 565.68 & 2.2580 & 514.368 & 2.0449 \\
\hline 0.0075 & 565.68 & 2.3562 & 511.5328 & 2.1594 \\
\hline 0.0078 & 565.68 & 2.4544 & 496.6336 & 2.2309 \\
\hline 0.0081 & 565.68 & 2.5525 & 489.7408 & 2.2545 \\
\hline 0.0084 & 565.68 & 2.6507 & 518.7392 & 2.2762 \\
\hline 0.0088 & 565.68 & 2.7489 & 597.0496 & 2.3619 \\
\hline 0.0091 & 565.68 & 2.8471 & 716.7552 & 2.5228 \\
\hline 0.0094 & 565.68 & 2.9452 & 852.1216 & 2.7236 \\
\hline 0.0097 & 565.68 & 3.0434 & 961.7088 & 2.9333 \\
\hline & & & & \\
\hline
\end{tabular}

\begin{tabular}{|l|c|c|c|c|}
\hline 0.0100 & 565.68 & 3.1416 & 1004.09 & 3.1416 \\
\hline 0.0103 & 565.68 & -3.0434 & 961.7088 & -2.9333 \\
\hline 0.0106 & 565.68 & -2.9452 & 852.1216 & -2.7236 \\
\hline 0.0109 & 565.68 & -2.8471 & 716.7552 & -2.5228 \\
\hline 0.0113 & 565.68 & -2.7489 & 597.0496 & -2.3619 \\
\hline 0.0116 & 565.68 & -2.6507 & 518.7392 & -2.2762 \\
\hline 0.0119 & 565.68 & -2.5525 & 489.7408 & -2.2545 \\
\hline 0.0122 & 565.68 & -2.4544 & 496.6336 & -2.2309 \\
\hline 0.0125 & 565.68 & -2.3562 & 511.5328 & -2.1594 \\
\hline 0.0128 & 565.68 & -2.2580 & 514.368 & -2.0449 \\
\hline 0.0131 & 565.68 & -2.1598 & 502.0544 & -1.9202 \\
\hline 0.0134 & 565.68 & -2.0617 & 482.2464 & -1.8234 \\
\hline 0.0138 & 565.68 & -1.9635 & 466.5408 & -1.7753 \\
\hline 0.0141 & 565.68 & -1.8653 & 464.6016 & -1.7591 \\
\hline 0.0144 & 565.68 & -1.7671 & 475.9168 & -1.731 \\
\hline 0.0147 & 565.68 & -1.6690 & 489.792 & -1.6664 \\
\hline 0.0150 & 565.68 & -1.5708 & 495.6864 & -1.570 \\
\hline 0.0153 & 565.68 & -1.4726 & 489.792 & -1.4752 \\
\hline 0.0156 & 565.68 & -1.3744 & 475.9168 & -1.4097 \\
\hline 0.0159 & 565.68 & -1.2763 & 464.6016 & -1.3825 \\
\hline 0.0163 & 565.68 & -1.1781 & 466.5408 & -1.3663 \\
\hline 0.0166 & 565.68 & -1.0799 & 482.2464 & -1.3182 \\
\hline 0.0169 & 565.68 & -0.9817 & 502.0544 & -1.2214 \\
\hline 0.0172 & 565.68 & -0.8836 & 514.368 & -1.0967 \\
\hline 0.0175 & 565.68 & -0.7854 & 511.5328 & -0.9822 \\
\hline 0.0178 & 565.68 & -0.6872 & 496.6336 & -0.9107 \\
\hline 0.0181 & 565.68 & -0.5890 & 489.7408 & -0.8871 \\
\hline 0.0184 & 565.68 & -0.4909 & 518.7392 & -0.8654 \\
\hline 0.0187 & 565.68 & -0.3927 & 597.0496 & -0.7797 \\
\hline 0.0191 & 565.68 & -0.2945 & 716.7552 & -0.6188 \\
\hline 0.0194 & 565.68 & -0.1963 & 852.1216 & -0.4180 \\
\hline 0.0197 & 565.68 & -0.0982 & 961.7088 & -0.2083 \\
\hline & & & & \\
\hline
\end{tabular}

\section{CONCLUSION}

In this paper it is described that the phasor estimation of the distorted waveform with GPS time stamping. Due to the GPS time stamping of every sample it is possible to calculate the accurate the power spectrum, angles of the different locations. The sampling clock is achieved by using GPS NEO6MV2 which is generating required number of sampling pulses per second by Arduino Uno based GPSDO. The PMUs measured values are precisely $(0.3125 \mathrm{msec})$ time stamped. This is very helpful to system operator to know the exact state of the system at any instant to take necessary actions against abnormal conditions.

\section{REFERENCES}

1. A. G. Phadke and J. S. Thorp, Synchronized Phasor Measurements and Their Applications. New York, NY, USA: Springer, 2008.

2. Xiaodong Zhao, David M. Laverty, D. John Morrow and Kieran McLaughlin, "GPS-Disciplined Analog-to-Digital Converter for Phasor Measurement Applications," IEEE Trans. Instrum. Meas., VOL. 66, NO. 9, September 2017

3. W. Yao et al., "A novel method for phasor measurement unit sampling time error compensation," IEEE Trans. Smart Grid, to be published, doi 10.1109/TSG.2016.2574946.

4. A.G. Phadke, "Synchronized Phasor Measurements in Power Systems", IEEE Computer Applications in Power, Vol. 6, NO. 2, pp 10-15, April 1993.

5. M. Prasad, K. N. Satish, K. S. Meena, and R. Sodhi, “A synchrophasor measurements based adaptive underfrequency load shedding scheme," in Proc. IEEE Innov. Smart Grid Technol. Asia (ISGT Asia), May 2014, pp. 424-428.

6. A. G. Phadke and B. Kasztenny, "Synchronized phasor and frequency measurement under transient conditions," IEEE Trans. Power Del., vol. 24, no. 1, pp. 89-95, Jan. 2009.

\section{Published By:}

Blue Eyes Intelligence Engineering \& Sciences Publication

(C) Copyright: All rights reserved.

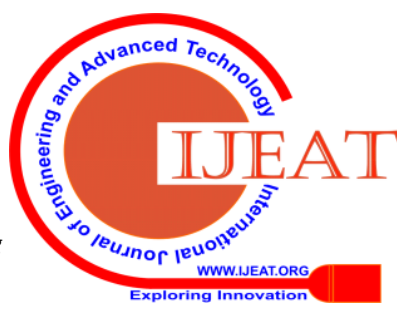


7. $\quad$ R. O. Burnett, M. M. Butts, T. W. Cease, V. Centeno, G. Michel, R. J. Murphy, and A. G. Phadke, "Synchronized phasor measurement of a power system event," IEEE Trans. Power Syst., vol. 9, no. 3, pp. 1643-1650, Aug. 1994.

8. Megha G Krishnan, S Ashok, "Implementation of Recursive DFT algorithm for Phasor Measurement Unit (PMU)" IEEE International Conference on Engineering Education: Innovative Practices and Future Trends (AICERA 2012).

9. Vi Microsystems Pvt Ltd. "MICRO-2812 Technical Reference manual version 3.0"

10. A. H. Nielsen, K. O. Helgesen Pedersen, and O. Samuelsson, "An experimental GPS- based measurement unit," in Proc. Nordic Baltic Workshop Power syst. Tampere, Finland Feb. 4-5, 2002, pp.1-6.

11. D. M. Laverty, D. J. Morrow, R. Best, and M. Cregan, "Anti-islanding detection using synchrophasors and Internet protocol tele-communications," in Proc. 2nd IEEE PES Int. Conf. Exhib. ISGT Europe, Dec. 5-7, 2011, pp. 1-5.

12. Debashish Mohapatra, "Development and Hardware Implementation of a Phasor Measurement Unit using Microcontroller" thesis of Master of Technology, NIT Rourkela.

13. Antonello Monti, Carlo Muscas, Ferdinanda Ponci, Phasor Measurement Units and Wide Area Monitoring Systems. Elsevier ISBN: 978-0-12-804569-5.

\section{AUTHORS PROFILE}

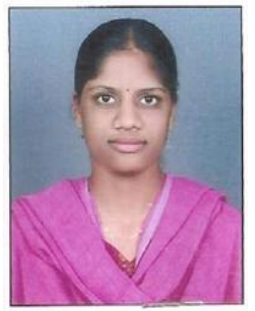

R. Alekya is working as a Asst. Professor in the Department of ECE, St. Martin's Engineering College, Hyderabad, India. Received the Bachelor of Technology degree in Electronics\& Communication Engineering from Ellenki College of Engineering and Technology (Jawaharlal Nehru Technological University Hyderabad) in 2009 and Master of Engineering degree in Embedded Systems from Stanley College of Engineering and Technology for Women (Osmania University Hyderabad), India in 2013. Area of interest is Digital Signal Processing, Embeddedsystems.alekyaa07@gmail.com

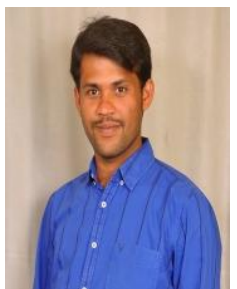

Ravi Ponnala is working as a Asst. Professor in the Department of EEE, Vasavi College of Engineering, Hyderabad, India. Received the Bachelor of Technology degree in Electrical \& Electronics Engineering from Vidya Bharathi Inistitute of Technology (Jawaharlal Nehru Technological University Hyderabad) in 2010 and Master of Technology degree in Power Electronics \& Electric Drives from Vardhaman College of Engineering (Jawaharlal Nehru Technological University Hyderabad), India in 2013. He is currently research scholar in Koneru Lakshmaiah Education Foundation (K.L.E.F.) deemed to be University, Vijayawada, India. Area of interest is Wide area power system monitoring and protection in dynamic state using synchronized phasor measurements with less data storage system, Live phasor representation of real power system, Development of smart grid model test bed system. ravi.ponnala237@gmail.com

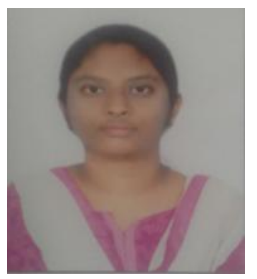

B. Shiny Sucharitha is working as a Asst.Professor in the Department of ECE, St.Martin's Engineering college, Hyderabad, India. Received the Bachelor of Technology degree in Electronics \& Communication Engineering from DRK Institute of Science and Technology (Jawaharal Nehru Technological University Hyderabad) in 2016 and Masters of Technology degree in Digital Electronics and Communication System from Mahatma Gandhi Institute of Technology(Jawaharal Nehru Technological University Hyderabad) in 2019. Area of interest is in Digital Signal Processing, Communication.shinylucky5@gmail.com

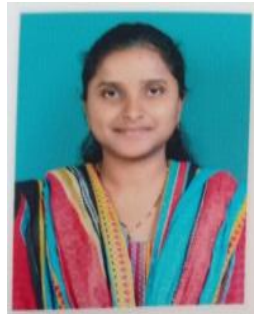

Aleti Soumyais working as a Asst. Professor in the Department of ECE, in St. Martin's Engineering College, Hyderabad, India. Received the Bachelor of Technology degree in Electronics \& Communication Engineering from Nalla Narasimha Reddy Educational societies (Jawaharlal Nehru Technological University Hyderabad) in 2013 and Master of Technology degree in VLSI System Design from CVSR College of Engineering (Autonomous) India in 2016.Area of interest is in Digital Signal Processing,VLSI.soumyayadama@gmail.com 